\title{
Importation of Chinese Innovation to Pakistani Firms in China Pakistan Economic Corredor
}

\section{Rehan Ullah*}

School of Business Administration, Southwestern University of Finance and Economics, Chengdu Sichuan, China

\begin{abstract}
At first, the China-Pakistan Economic Corridor (CPEC) initiative was treated with some uncertainty. Over time, the critics were proved wrong as the CPEC initiatives. With many large scale projects to be done, an influx of Chinese firms as well as specialized laborers into Pakistan meant that the importation of technological skills and innovation benefits is a reality. China having anchored its economic success story on outstanding technological skills and innovation makes Pakistan a possible beneficiary. The CPEC was based on friendship, open communication, and intensity of knowledge exchange. Then, given that the Pakistani economy had been struggling and the local business environment characterized by low innovation impetus, the China-Pakistan Economic Corridor initiative was a dream comes true. Since the signing of the CPEC agreement, the implementation phases are ongoing. Subsequently, the local Pakistani firms are now better place to get innovation support from Chinese who desire to improve regional trade and economies. With few researchers pessimistic about the CPEC agreement, compelling evidence points that local Pakistani entrepreneurs, employees and investors have warmed up to Chinese technologies with a view of transforming the local firms for speedy and efficient growth and development.
\end{abstract}

Keywords: Innovation benefits; Technological skills; Efficient growth; CPEC; China-Pakistan

\section{Introduction}

For decades, Pakistan and China have had long standing military and diplomatic ties. Often, the paths of diplomacy have crossed and other times both nations have worked towards securing a better and common future. In the economic sense, however, there has been no mammoth investments to ensure a join future; at least, not until the unveiling of the ambitious China-Pakistan Economic Corridor (CPEC). So, on the Monday of April 20, 2015, Chinese President Xi Jinping together with the Pakistani Prime Minister Nawaz Sharif jointed launched CPEC through signing 51 Memorandums of Understanding and agreements with an immense value of $\$ 46$ billion [1]. The enormous transport corridor project would involve the construction of a series of roads, ports, power projects, and other infrastructural projects to better the China-Pakistan networks and growth [2].

In the middle of this massive investment between the two nations, one question arises; whether the boost China's ambitious Belt and Road Initiative and the transformation of Pakistan economy would be realized [3]. This report does not only base on benefits attributed to the Pakistan economy by specifically whether the Chinese innovation will be imported and whether the local Pakistani firms will get innovation benefits for enhanced growth. In this report, details of CPEC and specifically innovation issues are adequately discussed with a strong argument that the investment bears endless innovation opportunities that can transform the landscape of local Pakistani firms including the Small and Medium enterprises.

\section{Research participants}

This research is mainly directed to the business owners, investors, shareholders of Pakistani firms and the general public- the citizens. It seeks to unveil whether the nature of technological innovation in Pakistan will increase following the unveiling of the ambitious ChinaPakistan Economic Corridor project. However, as would be explained in the methodology section (see chapter 4), this study did not involve any actual persons. It draws data from already done scholarly studies that involved a wide range of participants. In other words, no person participated, first hand in the collection of data since this research did not utilize any forms of primary research.

\section{Literature Review}

\section{Brief overview of the CPEC}

Drawing from Ahmad et al. [4], the People's Republic of China has enhanced its growth and development trade influences within the and South Chinese Ocean and Indian region. Scholars and economic researchers have named this as the country's 'String of Pearls Strategy' (SOP). The launch of the CPEC with Pakistan is perceived as part of the SOPs and the Belt and Road Initiative. The $\$ 46$ Billion different projects in Pakistan not only seek to deeply connect the two nations (through the sea Port of Gwadar with Kashgar) but also enable the influx of chines firms to invest in Pakistani. Ever since its launch, within the South and Central Asia, the CPEC has been termed as a game-changer, especially in the fact that it offers unlimited opportunities for economic interaction and integration between Pakistan and China. Pakistani Prime Minister Abbas was quoted saying that the 'Pakistan-China bilateral ties are time tested; our relationship has attained new heights after the China-Pakistan Economic Corridor that is a game changer for the region and beyond [3]. Then, to some extent, some researchers have noted that Pakistan's link with China will bring along technological innovation influx to make Pakistan have a superior economy than its arch-rival, India [5]. This argument is formed on the premise that China is a fast growing economy that has leveraged on its modern

*Corresponding author: Rehan Ullah, School of Business Administration, Southwestern University of Finance and Economics, Chengdu Sichuan, China, Tel: +8615802875733; E-mail: rehanmalakand@gmail.com

Received October 11, 2018; Accepted October 31, 2018; Published November 06, 2018

Citation: Ullah R (2018) Importation of Chinese Innovation to Pakistani Firms in China Pakistan Economic Corredor. J Bus Fin Aff 7: 358. doi: 10.4172/2167-0234.1000358

Copyright: @ 2018 Ullah R. This is an open-access article distributed under the terms of the Creative Commons Attribution License, which permits unrestricted use, distribution, and reproduction in any medium, provided the original author and source are credited. 
technological innovation across all sectors, from civil engineering, architecture, agribusiness, and energy among many others [6].

In the same view, the Global Capital Report (2016) projects an optimistic view that Pakistan, based on CPEC opportunities, is poised to get into the top leagues of the nations experiencing great economies [7]. Terming the $\$ 46 \mathrm{bn}$ investment as a 'corridor of opportunity', the report further applauds Pakistani's link with Beijing as capable of bringing along capital and technology. As a result, the Pakistan will witness enhanced growth not only through the short term foreign direct investment but also in the long term acquisition of technological innovation that would transform Pakistan form a nation composed of fragmented provinces into a sole, consolidated and up scaling economy [5]. The aim of the corridor as enshrined in the Long Term Plan (LTP) for China-Pakistan Economic Corridor (2017-2030) report is improving connectivity, communication, trade as well as cooperation between the two nations and neighbouring nations [1].

Finally under this subsection, it is critical to reflect on the utterances of the Pakistan leader at the signing of the trade treaty. First the Pakistani Premier Nawaz Sharif, acknowledged that the China-Pakistan the corridor 'would transform Pakistan into a regional hub [8].' He also recognizes that the investment's benefits are two-way and would enable China get not only cheaper and shorter routine for trade exploration in many parts of Asia, in the Middle East as well as to Africa. Shariff noted that, 'friendship with China is the cornerstone of Pakistan's foreign policy [8].' Through this statement, the Prime Minister recognized that the ties between two nations are based on eternal friendship so that each realized their goals. Indeed, the corridor, which would entail networks of rail, roads and pipelines, would readdress the economic challenges such as in Pakistan's poor Baluchistan province in which long-running separatist rebellions have slowed economic development of Pakistan firms [8]. From the face of it, the assertions by Shapiee and Idrees that the corridor is Pakistani's 'most valuable dream' are well founded [9].

\section{Defining innovation \& its justification to Pakistani firms}

Drawing from Javaid and Rashid [10], the prominence of China both in the Asian Pacific region and the rest of the world has become noticeable in the recent decades. Especially in the economic spheres China has become a success story not only to the region but to mature economies like the US. It is not surprising to hear scholarly projections that China would overtake the US to be the most enormous economy in the next few years. Yet, one thing is for sure; China's economic power growth and expansionist plan has anchored on technological innovation [11]. As noted by Jilani [12], the CPEC between China and Pakistan which is now in its implementation phase echoes the technological innovative power that China wishes to share with her neighbour. Without any doubt, Ghani and Sharma (2018) who scrutinizes the post-CPEC trading at the Karachi Stock Exchange, plainly admit that shareholders and entrepreneurs of the Pakistan firms will stand to reap big from the China-Pakistan Economic Corridor agreement [13].

But what is innovation precisely? Innovation is often a generalized and poorly understood term. Truly, it has attracted thousands of definitions. According to Greenwald, a Contributor to the Forbes, innovation is about having new lines of thinking to as to create more value and relevance of a brand to its clients [14]. It implies that a firm which continually upholds innovation, it gets unique ways to gain profits by understanding and availing new, fastest, reliable, more fashionable as well as more convenient products and services.
Additionally, Kogabayev and Maziliauskas understands innovation, in the business context, as finding new ways to offer products and create value, relying on technology to save time and costs as well as improve business processes [15]. Further on, Manuylenko et al., cites Tsvetkov who terms innovation as a process of where novelty is implemented to result into meaningful value to target consumers [16]. In this sense, innovation can be understood as an object that is embedded into production so that the end result is more valuable, reliable and relevant to the consumers.

Thus talking about the value creation of CPEC to the Pakistan firms, the innovation under review is the technological innovation. Pakistan, a multiethnic society with largely Indo-Iranian speakers has attempted to upscale the business environment. Yet, limited technological innovation has been a major hindrance to economic breakthroughs. In fact, Aslam, and Hasnu, [17] argue that entrepreneurs as young as students in Pakistan are enthusiastic to venture into entrepreneurship but technological innovation is one major issue that hinders their potential. Despite the individuality and creativity of the young people in Pakistani, low levels of innovation. In the same breath, Ahmed stresses that despite a slow increment in the tech start-ups and disruptive technologies in Pakistan, limited innovation-based findings through incubations, technical and financial assistance are noticeable in the country [18]. Researchers in the recent decades have pushed for more avenues to foster innovation among the young people and entrepreneurs in the Muslim nation of Pakistan.

Still on the innovation landscape in Pakistani, Hussain et al., recognize that 'Pakistan's main problem is less entrepreneurial activity and I strongly believe that Pakistanis have more entrepreneurs than employees (2011:45).' Here the author talks about technology-based entrepreneurship and are empathic on how the low levels of innovation have made it impossible for a nation to realize milestones. Even while the country realizes an increasing number of Small and Medium Enterprises (SMEs), the thirst for innovation is evident and would spur these institutions to create more value to domestic market which ultimately translates to improved economic growth [19]. Importantly, the reflection of the innovation landscape in Pakistan lays the ground to justify for the need to infuse in more innovation. And yet, highly performing economies such as Chinese economy attribute their successes on continued innovation. In this sense the CPEC agreement offer a vital link for importation of technological innovation to a country that so desires innovation to spur its economic growth, from its lowest entrepreneurial levels to large scale sectors such as manufacturing and civil projects.

\section{Threats and criticisms to innovation importation}

Nonetheless, some researchers have cautioned that the influx of innovation, skills and technologies via the China-Pakistan Economic Corridor initiative would not as smooth as how the Silk Road appears. To the critics, it is a long road that meanders; characterized by competition, exploitation and sabotage. First, Mehmood et al. tend to believe there is an evil neighbour next door [6]. They cite reports that India, which not pro-China, is working behind the scenes to sabotage the Pakistan-China unity. Reportedly, it is engaged in a series of clandestine operations and activities with a view of destabilizing the CPEC agreements. Researchers who share this view perceive that the dragon's expansion plan should be tamed, and so should Pakistan be stopped to growth so fast. Pakistan is very populated with close to 200 million inhabitants making it the second highly populated Muslimmajority state on the globe [20]. As acknowledged by Adnan and Fatima [11], due to ever growing diplomatic ties between India and the 
US, there is a tendency to make policies that aim to destabilize China's supremacy in South Asia. While it is quite unclear, it is possible for the same to happen to Afghanistan (bordering Pakistan in the northwestern side) and Iran (in the west). Even the Anti-state Baloch insurgents pose a considerable threat to the success of Pakistani CPEC [21].

Secondly, opponents believe that since China is the dominant partner in this pact, there is a tendency to exploitation for its own gains. For instance, they have questioned why China has to bring about 0.6 million Chinese workers in Pakistan when the local workforce can be very impactful in furthering the China-Pakistan Economic Corridor agenda [22]. Given this huge workforce, as they argue, it would be difficult for Pakistan to have an equal share of opportunities. For some, this huge population, the Pakistani people and firms will have a slim change of tapping the technological innovations that China brings along. They believe it is because a huge concentration of foreign workers denies the opportunities for the locals to learn. Then, if the benefits to Pakistan are shrunk it means it would take considerably long to pay off debts and get even. Aamir [22] cites one of the recent reports from a Pakistan-based brokerage house which noted that the country would pay China an estimated US $\$ 90$ billion in the course of three decades. That is a sad situation, which would deny the economic benefits including benefits from Chinese technologies and other forms of innovation.

Then, lastly, the foreign interference has been noted as a possible hindrance to innovation acquisition of Pakistan in the CPEC framework. American companies have been cited as having potential to bringing unhealthy competition [6]. The US government has been perceived as able to facilitate entry of large sized firms including highend multinationals in Pakistan. Already there are reports that firms like General Electric, and Caterpillar as well as topnotch consultant corporates like McKinsey have an interest to invest in the Post-CPEC agreement Pakistan [20]. But why should Pakistan worry about these large firms yet they would bring in millions of dollars in foreign direct investments? The worry is all about edging away the local firms. These well established firms would capitalize on CPEC infrastructure, renewed energy sector, and manufacturing sector among others [13]. In their dominating presence, the medium and small sized firms will have no place to share in Chinese interactions. They US firms would become immediate beneficiaries of the technologies and business opportunities as opposed to the Pakistan counterparts. If this were to happen then the win-win situation envisioned by 'The economic benefits of the modern silk road' Report will not be easily achieved since the local experience of Pakistani firms and the acquisition of technical skills of Chinese companies will be an illusion [23]. Nevertheless, odds are in favor of Pakistan with estimates of achieving a 2.00 percent growth in GDP due to CPEC initiative [12].

\section{Technological innovation benefits of CPEC to Pakistan}

Reporting for South China Morning Post, Adnan Aamir on $13^{\text {th }}$ September 2017 asked a very important question; who will the CPEC agreement between China and Pakistan really benefit [22]. In trying to answer the question, the reporter established that Pakistan had huge innovation and skills benefits arising from the agreement. To offer brief background information, Pakistan has for decades relied on the foreign remittances as well as aid from the west to power up its often-struggling economy. Therefore, in the advent of signing the CPEC, many insiders described the new investment as a blessing to the country. At first, it was evident that a huge influx of Chinese workers would come into Pakistan alongside firms to work on the infrastructural projects as provided in the agreements. As such, it brought jitters and anxieties that Pakistanis will have their jobs robbed in a deal that seemed to benefit the Chinese more than Pakistan locals.

Over the same, one report by the Federation of Pakistan Chambers of Commerce and Industry projected that the Chinese workers will outnumber their Pakistani counterparts by 2048. Upon completion, the report provided that Pakistan would witness an influx of slightly over than 600,000 Chinese workers every year [22]. And the worry was just far from employment alone; that the Chinese will disrupt the Pakistani culture, values religion and completely the way of life. But in the recent times, the huge influx of Chinese firms and workers has been understood as a blessing in disguise. It means that their innovation and skills will be crossing the border and remain in Pakistan in the foreseeable future [24]. In other words, the Chinese participation in the CPEC agreement means that there is assured technological skills and innovation destined to Pakistan. Then, over a long time, Pakistani firms will have a chance to leverage on these technologies for own survival and vibrancy in economic performance.

While the China-Pakistan Economic Corridor initiative mainly concerns with highways and energy, the associated skills and innovations have relevance in many sectors in Pakistan [5]. But first, highway technology is assured as Pakistan firms will take part, thus taking time to compare notes. For example, one highway getting into China at Khunjerab would cross through the Karakoram mountain range [24]. Here Pakistan firms in the civil engineering sector will encounter freshest civil engineering technology especially that involve complex and scapes. Then, the milestones in energy will entail establishment of 29 industrial parks as proposed that would entail 21 mineral zones as well as 27 SEZs. Such energy technologies when adopted by Pakistan firms will be spread throughout the nation which will realize speedy growth of the industry and trade sectors [21]. Then, the other sector is the agriculture sector oragri business. Here, the China-Pakistan trading will open up giving the chance for exportimport interactions. The Pakistan entrepreneurs will get a chance to adopt innovations in crop production, preservation and marketing. Then, in the long run, the Pakistan would realize an increase in exports, enhanced GDP, as well as record improvements in basic amenities, health and food security [21].

Researchers have argued that alignment to China is easier for Pakistani than the US. The latter has been pushing for anti-immigration as well as anti-Muslim sentiments in Pakistan. Education and training will be also improve given that between 2000 and 2014, the science and engineering graduates in Pakistan rose from 359,000 to 1.65 million [24]. Thus, with newer opportunities such as CPEC, offer new development training and employing the Pakistani young people in artificial intelligence, biotechnology robotics, and renewable energy, areas that Chinese prides on.

In addition to that, a formal report recently shed a light on the technological innovations and skills among other benefits that Pakistan will enjoy following the enactment of the CPEC. Titled, 'the economic benefits of the modern silk road: The China-Pakistan Economic Corridor' the report was jointly prepared by the Pakistan-China Institute and the Association of Chartered Certified Accountants [23] The report provides that Pakistanis have a 60,000 job allocation by 2015 and up to 800,000 jobs by the year 2030 . Then, due to the 21 energy projects, Pakistani will realize double amount of energy generation to boost businesses (that is up to 16,400 megawatts by completion of the CPEC initiative). The initiative will also bring special economic zones (such as supporting small scale farmers with finances and skills), promotion of tourism, transportation and trade [23]. But then, these 
numbers are not only in theory as by the end of 2017, the Pakistani economy grew by 5.3-percent (the all-time high in the past decade) [23]. Yet, all these milestones can be attributed to the silk roads, energy projects and many others under the China-Pakistan Economic Corridor agreement.

Still on the report, its author Malik Mirza made a very important declaration to the Pakistani firms, employees and entrepreneurs. Drawing from Xinhua [23], Mirza argued the Pakistani firms to adapt to new ways of doing business with China in terms of resource allocation, specific technologies to improve trading environment, approach to risk management and taking advantage of the SinoPakistani bilateral ties. Besides, specific projects such as the Belt and Road Initiative offer the seamless platforms that support businesses such as moving products between the two countries. Over the same, Wang provided that Pakistani firms need to compete healthily with high-end manufacturing companies from China [20]. In the longrun, there partnerships will realize not only inter-firm exchange of knowledge and skills but also realize synergies in moving the Pakistani sectors forward. In emphasizing the main point, in the long term, Pakistani firms will enjoy the newer technological approaches and skill sets employed by the Chinese to further their development agenda.

In carrying out a SWOT Analysis on the China-Pakistan Economic Corridor initiative, Mehmood et al. maintain that the variety of abilities, skills and innovative apaches gathered by the Chinese will institutionalize a sense of innovation that would boost entrepreneurship in Pakistan [6]. Remember the business environment of Pakistan is largely deficient of innovation and working on the same will ensure speedy growth of business across the sectors [25]. In addition, Mehmood et al. provide that the China-Pakistan interactions will foster a strong commitment to growing business [6]. The prevailing weak economic incentives will be significantly removed as the Pakistani firms will have impetus to do far much more economically.

In the view of innovation importation into Pakistan, it is essential to outline that CPEC bears huge impacts in the fulfillment of the country's Vision 2025. As captured by Global Capital Report (2016) [7], under Pakistan's vision 2025 plan, the prime goal is to achieve a transformation of the country's economy into one of the ten best globally trading states. The main pillars in the attainment of this vision include among others, a modernized public sector, attaining food and energy security, having a robust and inclusive economy as well as democratic governance. The country has in the recent past pushed for entrepreneurial spirit, improving connectivity, as well as well has presence of an innovative and competitive knowledge economy [7]. As game-changing project, the CPEC is indeed taking Pakistan closer to the achievement of its vision 2025 plan. This mid-century plan would be achieved not by foreign aid dependence but in a strong embrace to technological innovation beyond its borders. Then, talking about cross border innovation importation and exchange, the ties with the peoples' republic of China is a great starting point.

In the final touch on how CPEC support vision 2025, it is clear that the project largely support infrastructural development in rails, highways, ports and has substantial attention to the country's energy sector [3]. Yet, these development projects will involve both the Pakistanis and Pakistani firms. Ultimately, among the gains realized will be having fostered trade and investment flows into Pakistan as well as improving both people to people and business to business connectivity [9]. In this regard, it is not farfetched to argue that as the Chinese come into Pakistan, they will bring along skills, interactions, technological innovations across the sectors so that the local trading environment is more awakened and works with the spirit of fast-pacing the road to vision 2015 .

\section{Research Methods and Equipment Used}

Firstly, this is a qualitative form of research study. A qualitative study is one that seeks to understand or unveil non-qualitative aspects among the study population. It studies trends, behaviors, beliefs, and values among others. More precisely, Melendez argues that qualitative researchers aim to attain a more comprehensive understanding of those activities that relate to human behavior and especially how such attributes continually define the behaviour [26]. In this study, the research seeks to unravel the trends among the Pakistani firms after the signing of CPEC agreement to ascertain if they perform better off after acquisition of the technological innovations. As a social science research method (also called market research) this qualitative study seeks to answer the how and why in relation to technological innovation influx in Pakistan [27].

Then, as mentioned before, this study utilized only the secondary data sources. This is a type of data extracted from already done studies. In a quite overview of its pros and cons, Cheng and Phillips provide that; first, use of secondary data is cost saving [28]. It is because such data is readily available, and a researcher can get access to it quite effortless. So, there is also time saving to rely on secondary data. Then, time-saving is also attributed to money and thus a researcher spend quite little to get tones of data sets to be used in a study. Importantly, use of secondary data allows for longitudinal comparisons so that it results into more integrity and reliability of the outcomes [28]. This advantages formed basis for choice of the secondary data. On the flipside, one relying on secondary data can adopt the inherent errors and mistakes of previous researchers. Yet, in this study, data has been cautiously collected from reliable sources to minimize on such errors. Recent most data has also been picked to remove the problem of obsoleteness.

The vital equipment used to gather the secondary data include the peer reviewed journal sites. Notable journals here include Journal of South Asian Studies, Journal of Entrepreneurship, Management and Sustainable Development, International Journal of Economics and Finance and Journal of Business and Public Administration among many others. Policy documents have been also incorporate such as Long Term Plan for China-Pakistan Economic Corridor (2017-2030) that details the CPEC plan [29]. In addition to that, the Google search engine has been employed to gather data from credible websites such as The Express Tribune, China Daily, Forbes, Reuters, Encyclopedia Britannica Inc., and the South China Morning Post. A handful doctorial thesis has also been employed to support data collection.

\section{Discussion}

The signing of the China-Pakistan Economic Corridor project signified a new awakening for the formerly struggling Pakistan economy. In the various projects and agreements under CPEC, Pakistan would realize a huge influx of Chinese firms as well as laborers to facilitate their completion. At the same time, may Pakistani firms will join the race, working closely with their Chinese counterparts in every step of the way. As acknowledged in priori studies, the CPEC seeks to empower both nations in various sectors such as energy, highway constructions, agribusiness, labor and entrepreneurship among many others [22,23]. It is only logical to argue that the Chinese would bring along other technologies in facilitating these projects. In turn, the Pakistani firms will get an opportunity to benefit from these technological innovations, for a long period of time. Notably, the onset 
of CEPC-embedded projects such as the Chinese Silk Road Economic Belt would mean Pakistani quickens its steps to achieving its vision $2025[3,30]$.

Further on viewpoints and SWOT analyses (such as by Mehmood et al.) on the CPEC have not shown contrary evidence of lack of innovation adoption [6]. The only threats captured such as insurgency and threat from neighbours are peripheral to the technological innovations. But then, it is practically impossible that Chinese firms would operate in meanness to deny Pakistani firms various technologies. As such, it is clear that the China-Pakistan Economic Corridor would imply a platform of shared ideas, knowledge and innovations in a two-way outfit. And since china has got more technological muscles, the most beneficiary in this partnership will be Pakistan. It then occurs that the owners and managers of the Pakistani firms need to maintain open-mindedness so as to tap maximally from the china-Pakistani interactions. As embedded in the 2016 Global Capital Report, the CPEC is indeed a 'corridor of opportunity' where the Pakistani firms need to leverage; given that the agreement is founded on friendship, communication and knowledge exchange $[5,8]$.

Now with sufficient evidence that there would be sufficient technological innovation dispensable to the Pakistani firms, it is logical to conclude that by getting innovation skills and benefits, the performance of local Pakistani firms will improve both in the medium term and long term. From this angel of view, the CPEC initiative is a doorway into a future where Pakistani firms get competitive from knowledge sharing with their Chinese counterparts. Yet, the effects are long range, sweeping through small sized entities to medium sized firms up to big players across different sectors. For instance, as already noted, small sized agribusiness firms will now be placed to incorporate Chinese technology in production, preservation and marketing. Then, they will ride on newly developed infrastructural developments such as the Silk Road, modern rails and ports to export products to china and other neighbours. Ultimately, the gains from the skills and innovations will be pronounced as Pakistan local business environment grows more competitive, robust and global.

\section{Conclusion}

On the Monday morning of April 20, 2015, Chinese president and Pakistani Prime Minister officially launched the China-Pakistan Economic Corridor (CPEC) initiative [29]. It composed of 51 agreements and MoUs that established a joint partnership between the two nations to develop energy, highways, ports and other amenities for the mutual economic benefits. More applauded than criticized, the CPEC initiative has come to be a dream come through. This research study has explored a great deal of evidence to show that the initiative bears tangible, medium-to-long-term innovation skills and benefits that would transform the Pakistani firms, small, medium and largesized. As more Chinese firms and laborers will get into Pakistani, the locals will have opportune moments for knowledge exchange to the benefits of the performance of local enterprises. While there have a handful of criticism to the success of the CPEC, especially on local firms, compelling evidence shows improved business environment with a rise in the GDP. With technological innovation deficit having proved a hindrance to the economic success story of Pakistan, the China-Pakistan Economic Corridor has a well-timed ticket for a way out of slow business growth and a struggling economy.

\section{References}

1. Rauf S (2018) China-Pakistan Economic Corridor (CPEC). Encyclopedia Britannica, Inc.

2. Kugelman M (2018) The China-Pakistan Economic Corridor and Energy Geopolitics in Asia. Wilson Center.

3. Chen X, Joseph S, Tariq H (2018) Betting Big on CPEC. European Financia review.

4. Ahmad S, Asmi F, Ali M, Rahman M, Abbas S (2017) China-Pakistan Economic Corridor: In the context of 'String of Pearl Strategy. Int J Bus Soc Res 7: 1-19.

5. Glogowski A (2016) China Pakistan Economic Corridor: Chances and challenges. International Multidisciplinary Scientific Conference on Social Sciences \& Arts SGEM, pp: 65-72.

6. Mehmood H, Mehmood S, Noman S (2017) SWOT Analysis of the ChinaPakistan Economic Corridor (CPEC). Quarterly J Chinese Studies 5: 42-64.

7. Global Capital Report (2016) Corridor of Opportunity: 522293. International Trade Financing, pp: 1-11.

8. Houreld K (2015) China and Pakistan launch economic corridor plan worth $\$ 46$ billion. Reuters.

9. Shapiee R, Idrees Q (2017) China Pakistan Economic Corridor (CPEC); Most valuable dream for Pakistan through economic integration in the region but may not become true without up-gradation of physical Infrastructure and Legal System! Sci Res J BLR 8: 481-498.

10. Javaid U, Rashid A (2016) China Central Asia Relations and opportunities for Pakistan. South Asian Studies: A Res J South Asian Stud 31: 157-175.

11. Adnan M, Fatima B (2016) China-Pakistan Economic Corridor: A Road to Development and its Challenges. South Asian Studies 31: 253-241.

12. Jilani MU (2017) Impact of China Pakistan Economic Corridor on the Economy of the Pakistan. IJS Int J Sci Eng Res 8: 1244-1278.

13. Ghani W, Sharma R (2018) China-Pakistan Economic Corridor Agreement Impact on Shareholders of Pakistani Firms. Int J Econ Financ 10: 148-158.

14. Greenwald M (2015) What Exactly Is Innovation? Forbes.

15. Kogabayev T, Maziliauskas A (2017) The Definition and Classification of Innovation. HOLISTICA - J Bus Public Adm 8: 1-14.

16. Manuylenko V, Mishchenko A, Bigday O, Putrenok Y, Savtsova A (2015) A Comprehensive Definition of the Concept of Innovation in Russian and International Science. Int J Econ Financ Issues 5: 1029-1037.

17. Aslam S, Hasnu A (2016) Issues and constraints perceived by young entrepreneurs of Pakistan. World Journal of Entrepreneurship, Management and Sustainable Development 12: 50-65.

18. Ahmed M (2016) Technology in Pakistan: A Slow March. The Diplomat.

19. Khan MJ (2017a) An Exploratory Evidence of the Types of Challenges and Opportunities Perceived by the Small and Medium Enterprises (SMEs) in the Apparel Export Sector of Pakistan. Abasyn J Soc Sci 10: 373-395.

20. Wang $L$ (2017) Opportunities and Challenges of the China-Pakistan Economic Corridor (CPEC) and Implications for US Policy and Pakistan. Asia Pacific Bulletin, pp: 1-2.

21. Khan H (2017b) China Pakistan Economic Corridor (CPEC): Benefits for Pakistan and comparison with Suez and Panama Canals. Doctoral Thesis Calhoun: The NPS Institutional Archive, pp: 1-116.

22. Aamir A (2017) Just who will the China-Pakistan Economic Corridor really benefit? South China Morning Post.

23. Xinhua Y (2018) China-Pakistan Economic Corridor brings economic benefits to Pakistan: Report. China Daily.

24. Burki S (2018) Bringing technological development into CPEC. The Express Tribune.

25. Hussain M, Afzal A, Asif M, Ahmad N (2011) Impact of Innovation, Technology and Economic Growth on Entrepreneurship. Am Int J Contemp Res 1: 45-55.

26. Melendez A (2011) Characteristics of Qualitative Research.

27. Kim H, Sefcik J, Bradway C (2016) Characteristics of Qualitative Descriptive Studies: A Systematic Review. Res Nurs Health 40: 23-42. 
Citation: Ullah R (2018) Importation of Chinese Innovation to Pakistani Firms in China Pakistan Economic Corredor. J Bus Fin Aff 7: 358. doi: 10.4172/21670234.1000358

Page 6 of 6

28. Cheng H, Phillips $\mathrm{M}$ (2014) Secondary analysis of existing data: opportunities and implementation. Shanghai Arch Psychiatry 26: 371-375.

29. CPEC (2016) Long Term Plan for China-Pakistan Economic Corridor (20172030).
30. Qureshi A (2015) China/Pakistan Economic Corridor: A Critical National and International Law Policy Based Perspective. Chin J Int Law 10: 777-799. 